\title{
Does Baclofen induce changes in testicular histology and seminal fluid analysis in rat?
}

\author{
L.I. Al-Allaf ${ }^{1}$, O.N. Sultan ${ }^{2}$, B.S. Saad-Allah ${ }^{2}$ and W.M. Al-Nuami ${ }^{3}$ \\ ${ }^{1}$ Department of Anatomy, ${ }^{2}$ Department of basic sciences, College of Dentistry, ${ }^{3}$ Department of Pathology, College of \\ Medicine, University of Mosul, Mosul, Iraq
}

\begin{tabular}{l} 
Article information \\
\hline Article history: \\
Received April 9, 2020 \\
Accepted May 14, 2020 \\
Available online March 15, 2021 \\
\hline Keywords: \\
Baclofen \\
Rat \\
Testes \\
Histopathology
\end{tabular}

Correspondence:

L.I. Al-Allaf

lumaallaf1971@yahoo.com

\begin{abstract}
Baclofen has a central acting effect, so clinicians have been utilized it chiefly for treating the spasticity of spinal origin. Nowadays, off-labeling use of baclofen with high doses is frequently increased. Despite of the extensive research studies on the effectiveness of baclofen, the reports on its histological effects on testes and on sperm parameters we insufficient. This work aims to assess the histological influences of baclofen on rats' testes and on several sperm characteristics after administration for 8 weeks. Twenty-two male rats at age of peripuberty (8weks) that were categorized into two groups. Group I (control group) includes 10 rats which were gavaged with $1 \mathrm{ml} /$ day of distilled water daily. Group II (baclofen's group) includes 12 rats which were received baclofen $14.5 \mathrm{mg} / \mathrm{kg}$ for 8 weeks via gavage. At the end of the designed work, euthenization was done and the testes were excised from each rat, the epididymis samples were obtained and prepared for examination under light microscope. This study revealed that rats that were administered with $14.5 \mathrm{mg} / \mathrm{kg} /$ day of baclofen for 8 weeks showed changes in the sperms parameters with several testicular histological alterations in their sections in comparison with those of controls. The percentage of the live sperms of rats (baclofen's group was lower than that of control group). Features of sloughing inside seminiferous tubules' lumen are frequently seen among these sections with mild decrease in the diameter of seminiferous tubules. Evidence of decreased Johnsen's scores (spermatogenic index -SI) was noticed in some sections, and decreasing of the frequency of seminiferous tubules that possess spermatozoa was obviously noticed. Moreover, disorganization of seminiferous tubules is shown in these sections. In addition, sections of rats of baclofen group revealed features of necrosis of seminiferous tubules, presence of degenerated spermatogenic layer, features of apoptosis, and presence of gaps in the seminiferous epithelium of degenerated tubules. Different alterations of sertoli cells as vacuolation, and detachment sertoli cells are noticed in sections of rats that were administered with baclofen. The chronic administration of rats with $14.5 \mathrm{mg} / \mathrm{kg}$ with baclofen induced effects on sperm parameters and testicular histology. however, the testicular histological alterations were more obvious. Further works are needed to clarify mechanism that stands behind these effects.
\end{abstract}

DOI: 10.33899/ijvs.2020.126894.1411, (C2021, College of Veterinary Medicine, University of Mosul.

This is an open access article under the CC BY 4.0 license (http://creativecommons.org/licenses/by/4.0/).

\section{Introduction}

One of the most serious reasons of males' infertility is their incapability to get dynamically healthful sperms in a sufficient manner. The susceptibility of chemicals, drug or compound to impair reproductive processes in laboratory animals and human is of great concern to toxicologists and the public (1). Sexual development in the male rat post 
natally has been categorized into four stages: neonatal, infantile, juvenile, and the period extends from post-natal day 36 to 55 or 60 is named peri-pubertal $(2,3)$. In fact, the spermatogenesis and steroidogenesis has not fully clarified till now throughout the period of peri-puberty, which could be considered critically during reproduction and as a result it may more liable for several challenges especially the chemical one (4). Baclofen is a brand name of GammaAmino Butyric Acid Beta (GABAB) receptor represents the major metabotropic receptor that is responsible for the inhibition of mammalians' central nervous system (CNS) (5). Beside its position in CNS, GABA is also localized peripherally in several systems including organs that have endocrinologic functions like ovary, pituitary, and hepatic tissue. Previous articles mentioned that Gammaaminobutyric acid receptors may be identified in male reproduction system as testes, sperms, deferent ducts and epididymis (6). Baclofen ( $\beta$-chlorophenyl - GABA, Lioresal) is the selective agonist of neurotransmitter GABA that acts potentially in clinical practice (7). It has beneficial effects in treatment of muscles spasticity after spinal cord traumas, multiple sclerosis, and alcohol dependence with prevention of alcohol relapse (8). The rate of off-labeling use of overdoses of baclofen markedly raised as it is used nowadays for treatment of chronic hiccups and anxiety disorders (9). Although it is clearly determined that Gamma-aminobutyric acid system localized in reproductive systems, the reports of the effect of baclofen on reproductive function and testicular histology are scanty. There is a need to study its effect on the testes in animal models at peripubertal periods. This study aims to assess the influence of baclofen on the testicular histology and sperm parameters of male rat administered orally with $14.5 \mathrm{mg} / \mathrm{kg} /$ day $/ 8$ weeks started at peripubertal period.

\section{Materials and methods}

Analysis of data of twenty-two male rats at age of peripuberty (8weks) was performed in this work. Rats were obtained from Animal House of Veterinary College, University of Mosul, Mosul, Northern Iraq. They were housed at optimized condition according to Liu et al. (10). Mean temperature was $23^{\circ} \mathrm{C} \pm 1^{\circ} \mathrm{C}$ and with maintenance of diurnal light/dark cycle of 12 hours. Animals were provided with water and laboratory chow ad libitum and put in a manner of 5 rats per each cage following the experimental laws and policies approved by Ethical Committee of Medical Researches of College of Medicine, University of Mosul, and they were categorized in a random manner into two groups. Group I (control group) includes 10 rats which were gavaged with $1 \mathrm{ml} /$ day distilled water daily. They were housed during the experiment under the similar manners for 8 weeks. Group II (baclofen's group) includes 12 rats which were administered with baclofen $14.5 \mathrm{mg} / \mathrm{kg}$ for 8 weeks via gavage. Baclofen doses were justified to be in accordance with those of other authors (11). Observing of the rats in both group was done with recording of any sign of sudden toxic effects during first 24 hours of treatment.

\section{Sperm collection}

At the last day of the planned study (after $24 \mathrm{hr}$. of the final dose), euthenization with ether (12) was done and laparotomy performed. Then, both testes were obtained with their epididymis. Measurement of the weights of testes, epididymis (head, body and tail), prostate, and seminal vesicles was done. The cauda- epididymis was utilized for studying the sperms characteristics, while the testis (right) was prepared for histologic analysis. For all rats, two cauda epididymis were isolated with mincing, protecting inside the Petri dish (warm) which contained ten $\mathrm{ml}$ of salt balanced solution (Hank's) with temperature of $37^{\circ} \mathrm{C}$. Spermatozoa have been allowed for distribution inside the solution. Then the removing of cauda - epididymis were done after $20 \mathrm{~min}$, mild shaking of the suspension was performed for homogenization to be ready for light microscopic examination under a using $\times 400$ magnification (13).

\section{Sperm counting}

To calculate the sperm, dilution of $500 \mu \mathrm{L}$ of the sperm suspension as 1:10 in fixative solution of formaldehyde (phosphate buffered saline with 10 percent of formalin). Approximately, movement of ten $\mu \mathrm{L}$ of this solution was done inside the hemocytometer. Then the hemocytometer has been localized in the chamber (moist Petri dish) via a moistened filter papers and has put there for 7.5 minutes. Counting of the settling sperms was performed (counting of 4 small corners with situation of center squares in the biggest center square of the counting chamber) and assessment / two hundred fifty small hemocytometer's squares via an objective $\times 40(14)$.

\section{Techniques for evaluation of the sperm shape}

The assessment of normal sperm morphology was performed by the examination of an aliquot of sperm smears of left cauda epididymis and estimation of the sperm deformities. Eosin-nigrosine protocol was conducted to investigate normal morphology of sperms as adding of 1 drop of eosin-nigrosine to the suspended solution with mild mixing, and about three hundred sperms have been assessed per each slide to precise the head's abnormalities and tail's abnormalities (15).

\section{Protocol of sperm viability}

In order to assess the presence of sperm viability, or not, five percent of eosin Y stain in saline was used. Samples of forty microliters of freshly sperm's suspension were localized on a crystallized slide, mixing with ten $\mu \mathrm{L}$ eosin and microscopically identified. Alive sperms persisted without stain after the staining protocol. On the other hand, 
pink or red sperms were considered as dead. Two hundred sperms at least were identified in a random manner from samples of each rat in ten visual fields, and live sperms' percentage was recorded (16).

\section{Histopathological analysis}

After fixation of all excised testes by using Bouin's solution, routine histological procedure was done to obtain histological sections and stained with Harris hematoxylineosin (17), then they were prepared for examination under light microscope for blinded evaluation to treatment and any data.

\section{Qualitative analysis}

Testes from the control and treated animals were analyzed for any disorganization of cytoarchitecture of seminiferous tubules, the presence of vacuoles, gaps, and detection of any cellular abnormality in the seminiferous tubular epithelium. Furthermore, sloughing, and degeneration of seminiferous epithelium were also looked for. Examination of interstitial spaces also was done $(18,19)$. In addition, spermatogenic index-SI (Johnsen' scores) were used to analyze the effect of drug on spermatogenesis as the scores range from one to ten (19). The seminiferous tubules that looked inactive completely, they were considered as score one, while those that showed maximally active ( $\geq$ five luminal sperms) they were considered as score ten.

\section{Photography}

Histological sections were visualizing in Ernst Leitz Wetzlar microscope (Germany). The photomicrographs were taken in by using Leica microscope with Leica camera (Germany, HD, 1080, resolution 8.0 Mega pixels) attached using plan apochromatic objectives.

\section{Statistical Analysis}

Data quantitatively were offered with mean \pm standard deviation. Analysis of variance (One-way) and chi-square were utilized to precise the statistical significance between the 2 groups through SPSS package (Version 16, SPSS Inc., USA), A significance level of 0.05 was considered (20).

\section{Results}

All animals remain alive during the experimental work. At necropsy, no clear gross tissue abnormalities were observed of any animal. Analysis of sperm parameters in this study revealed that the percentage of the live sperms of treated rats which were administered with baclofen for 8 weeks was $65.4 \%$ compared with $68.6 \%$ in rats of control group, while the percentage of the dead sperms in rats of baclofen group was $34.6 \%$ compared with $31.4 \%$ in rats of control group (Figures 1-3), (Table 1).

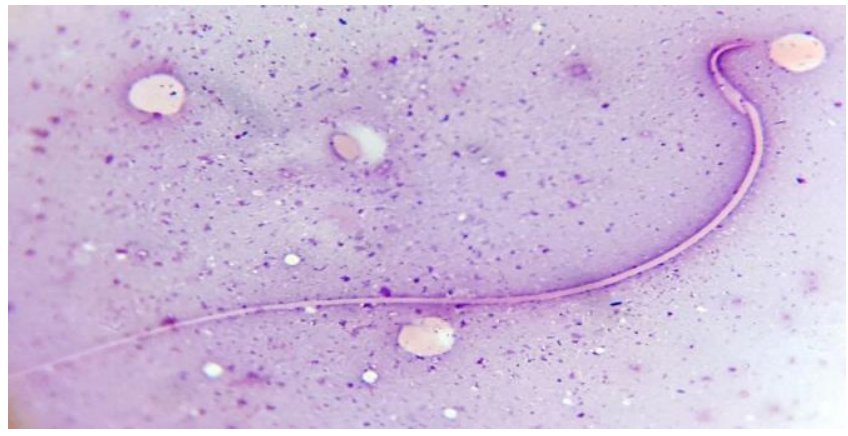

Figure 1. A photomicrograph of a sperm smear obtained from a rat from control group showed normal sperm (EosinNigrosine $\times 1000$ ).

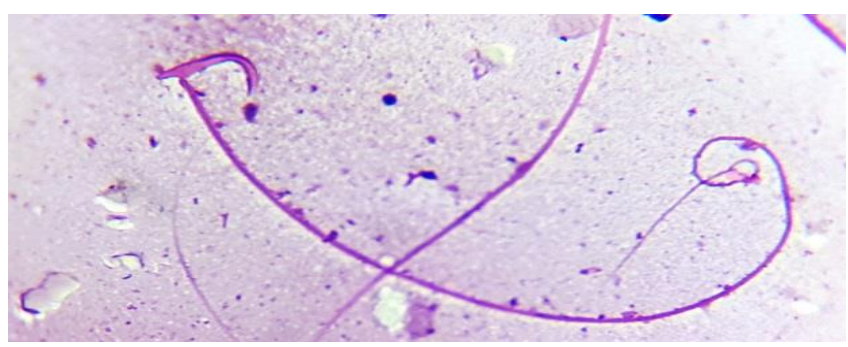

Figure 2: Photomicrograph of a sperm smear of a rat from baclofen group showed abnormal head and tail (EosinNigrosine $\times 1000)$.

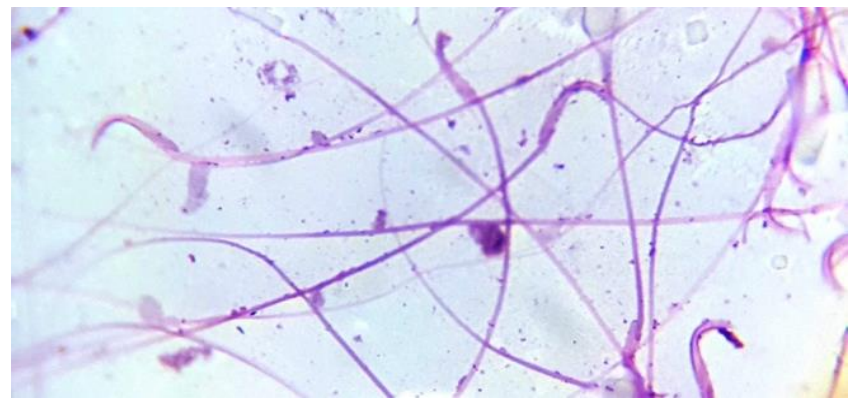

Figure 3: Photomicrograph of a sperm smear of a rat from control group showed abnormal head (Eosin-Nigrosine $\times 1000)$.

Table 1: Effect of baclofen on sperm count, percentage of live sperm, dead sperm, and abnormal sperm

\begin{tabular}{llllll}
\hline Groups & (n sperm) head of epididymis & \% live sperms & \% dead sperms & \% abnormal sperms & $\mathrm{P}$-Value \\
\hline Control & $1.42 \times 10^{6}$ & $68.6 \%$ & $31.4 \%$ & $7.6 \%$ & $\mathrm{P}>0.05$ \\
Baclofen & $1.52 \times 10^{6}$ & $65.4 \%$ & $34.6 \%$ & $6.4 \%$ & $\mathrm{P}>0.05$ \\
\hline
\end{tabular}


Histological analysis of the testicular sections obtained from control rats showed normal appearance of the seminiferous tubules (Figure 4). On the other hand, the current work revealed that sections obtained from rats administered with $14.5 \mathrm{mg} / \mathrm{kg} /$ day of baclofen for 8 weeks showed several testicular histological alterations in comparison with those of controls. Features of sloughing inside seminiferous tubules' lumen of the testes of the treated animals are frequently seen among these sections with mild decrease in the diameter of seminiferous tubules (Figure 5), while decreased spermatogenic index-SI (Johnsen's scores) was noticed in some of these sections. Mean Johnsen's scores in these sections was $6.5 \pm 0.1$ (Figure 6) as there is a decrease in the number of seminiferous tubules containing spermatozoa among testicular sections obtained from rats of baclofen group. Moreover, disorganization of seminiferous tubules is shown in sections obtained from rats of baclofen group (Figures 6 and 7), while retained spermatids with a decrease in the thickness of the spermatogenic layers are identified in some of these sections (Figure 8). In addition, light microscopic observations of sections of rats administered with $14.5 \mathrm{mg} / \mathrm{kg} /$ day of baclofen for 8 weeks revealed features of necrosis of seminiferous tubules as shown in figure 9, and even degenerated spermatogenic layers were noticed (Figures 6a, 7 and 10). Moreover, the results of this study showed that sections obtained from baclofen administered rats exhibited presence of cells with dense nuclei and esinophilic cytoplasm which are indicating presence of apoptosis (Figure 11). Apoptotic spermatogonia may manifest features of hyalinization, and hypereosinophilia with compressed deeply stained cytoplasm. Their nuclei showed indestincting features with occasional clear surrounding space resembled to cellular shrinking. There was also presence of gaps in the seminiferous epithelium of degenerated tubules (Figure 12). On the other hand, different alterations of sertoli cells were observed as vacuolation composed of variable size, separated, clear, rounded structures frequently localized directed to the basal membrane (Figures 12 and 13). Detached Sertoli cells were noticed in some sections (Figures 13 and 14), as well as, pyknotic nuclei (Figure 14 and 15), while apoptotic nuclei were identified clearly in some of these sections (Figure 16).

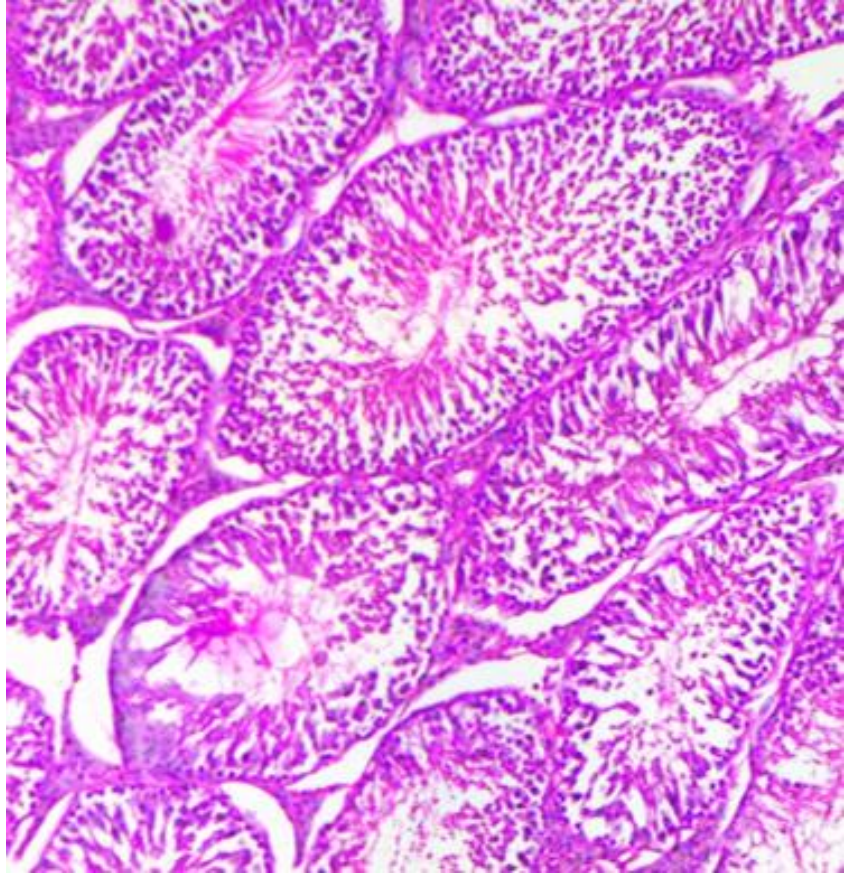

Figure 4: Photomicrograph of a section obtained from a rat from control group showed normal spermatogenesis $(\mathrm{H} \& \mathrm{E} \times 250)$.

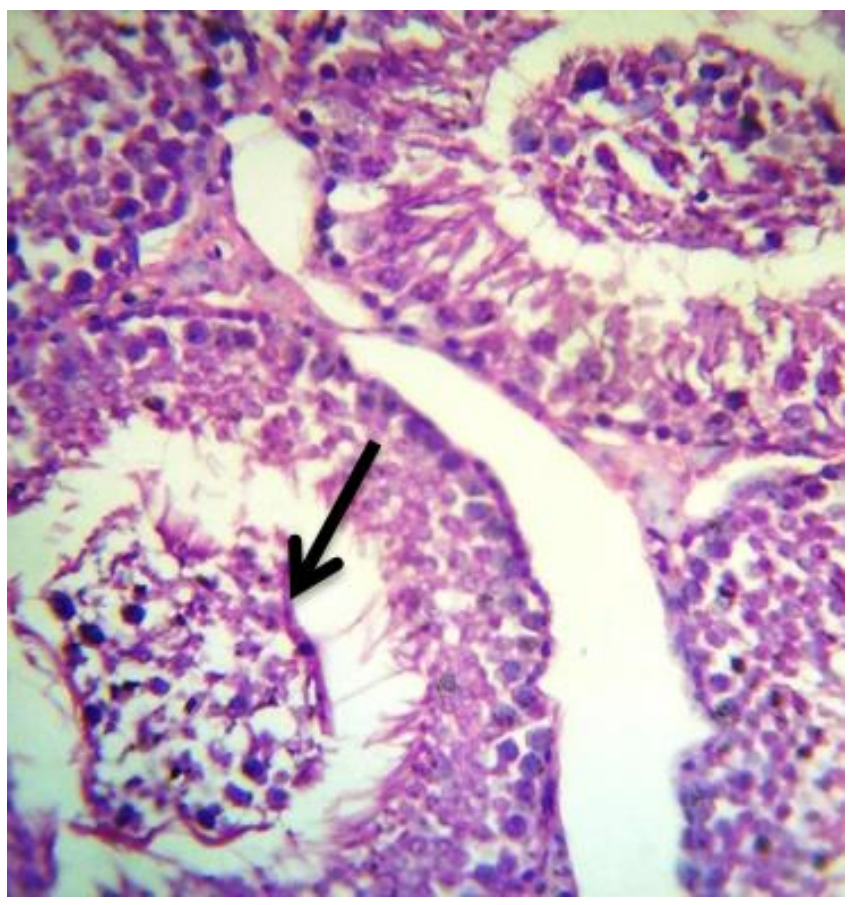

Figure 5: Photomicrograph of a section obtained from testis of a rat after treatment with $14.5 \mathrm{mg} / \mathrm{kg} /$ day of baclofen with features of sloughing (arrow) (H\&E×400). 


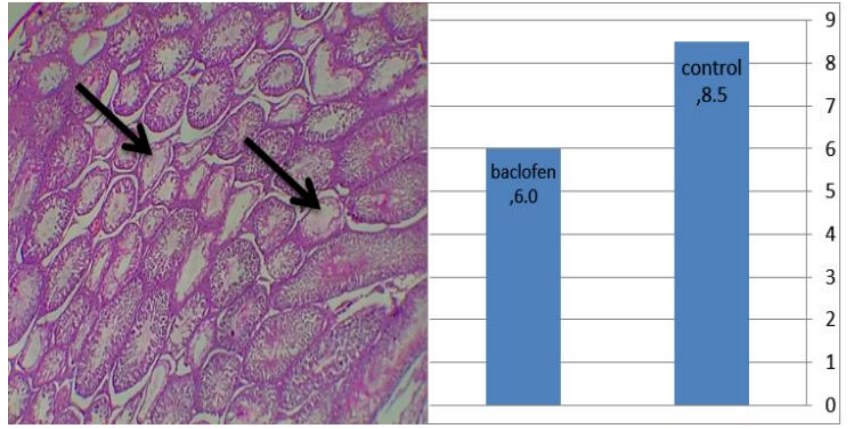

Figure 6: (a) Photomicrograph of a testicular section obtained from a rat after treatment with $14.5 \mathrm{mg} / \mathrm{kg} / \mathrm{day}$ of baclofen with decreased Johnsen's scores and degenerated spermatogenic layer (arrows) (H\&E×250). (b) Histogram of the spermatogenic index-SI (Johnsens' scores) of both study groups.

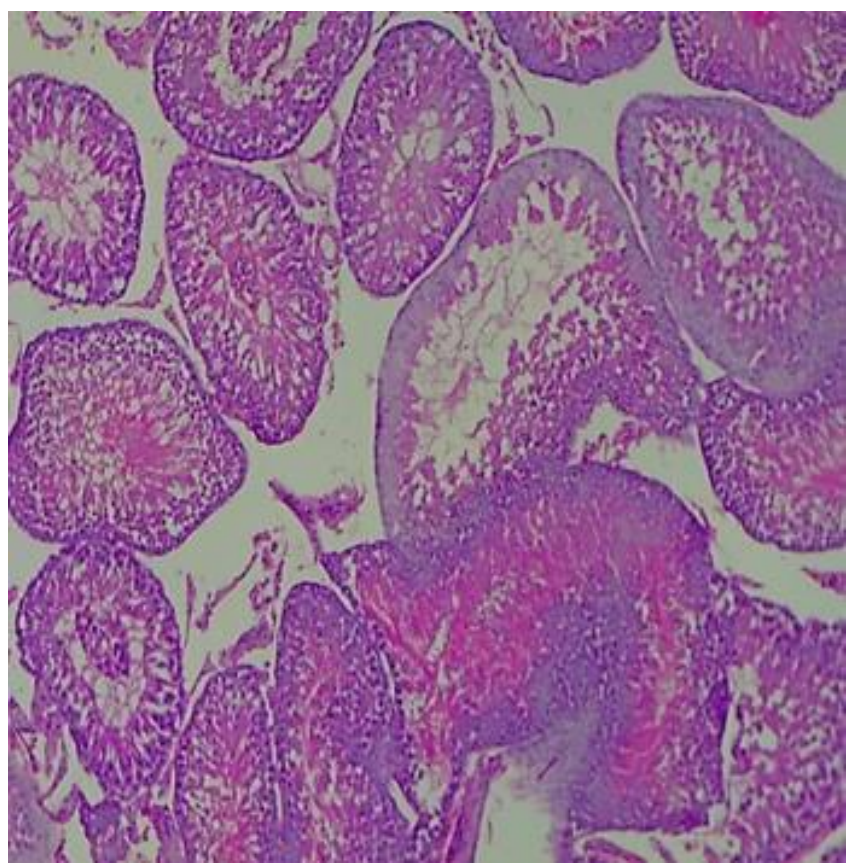

Figure 7: Photomicrograph of a testicular section of rat treated with baclofen with features of disorganization $(\mathrm{H} \& \mathrm{E} \times 250)$.

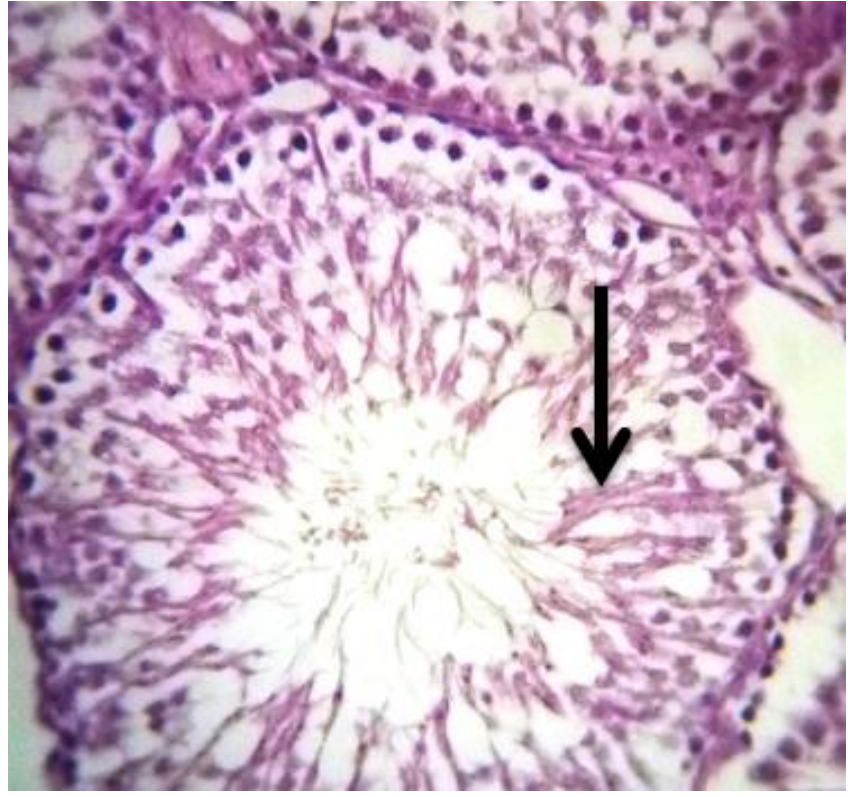

Figure 8: Photomicrograph of a testicular section of rat treated with baclofen with features of retained spermatid (arrow) (H\&E×400).

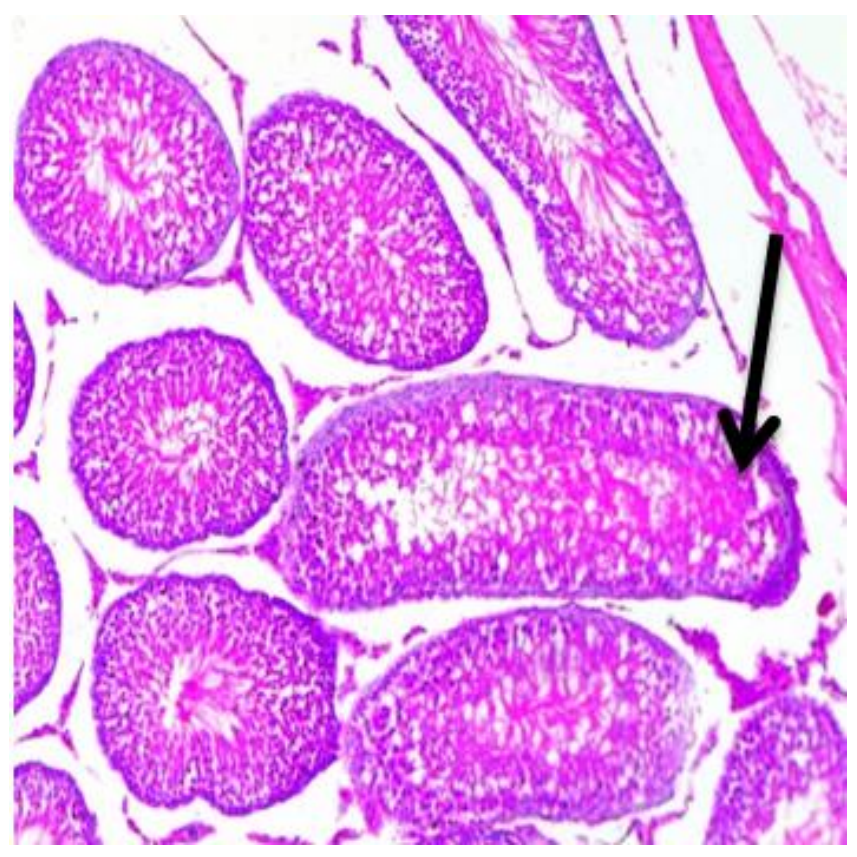

Figure 9: Photomicrograph of a testicular section of rat treated with baclofen with features of necrosis (arrow) $(\mathrm{H} \& \mathrm{E} \times 250)$. 


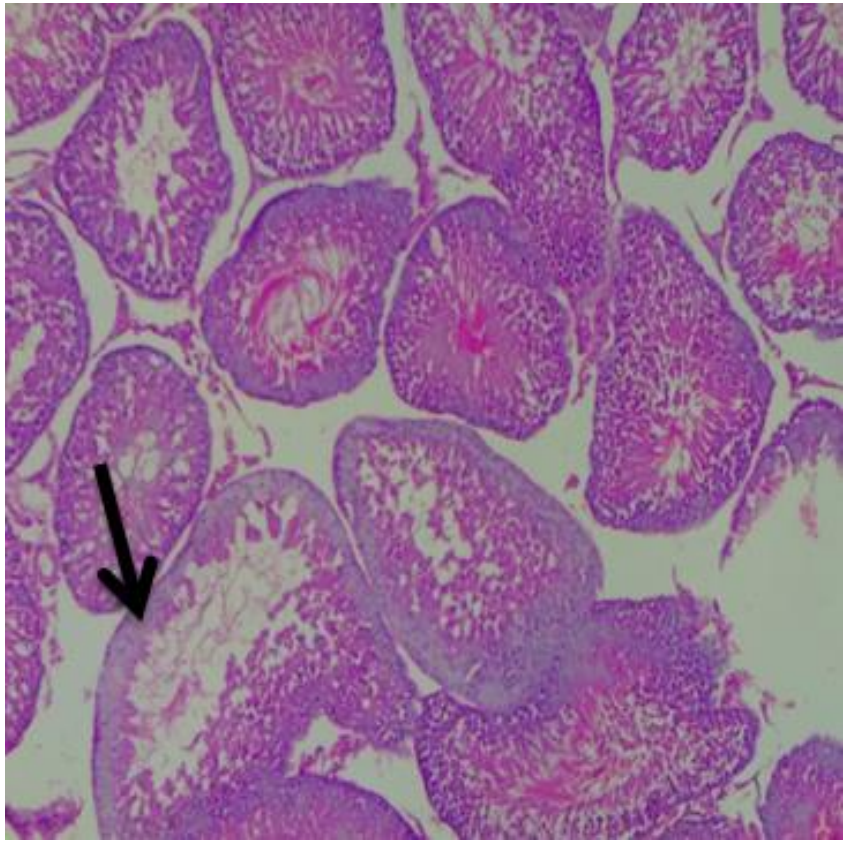

Figure 10: Photomicrograph of a testicular section of rat treated with baclofen with features of degeneration in spermatogenic layer (arrow) $(H \& E \times 250)$.

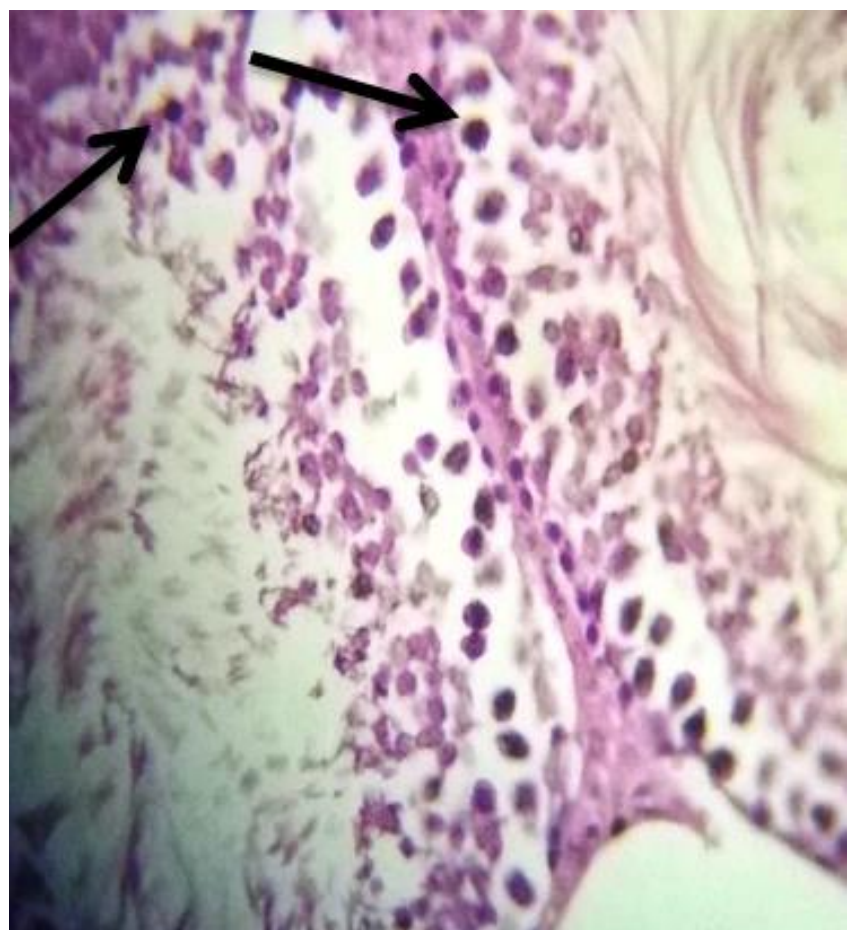

Figure 11: Photomicrograph of a testicular section of rat treated with baclofen with features of apoptosis (arrow), gaps in the seminiferous epithelium of degenerated tubules $(\mathrm{H} \& \mathrm{E} \times 400)$.

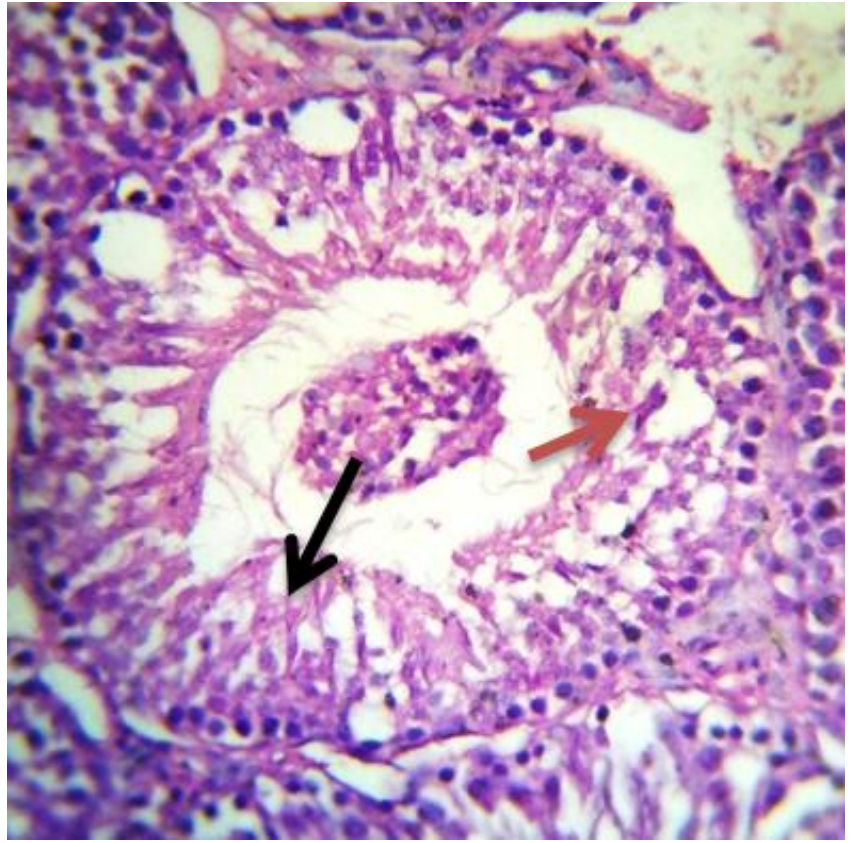

Figure 12: Photomicrograph of a testicular section of rat treated with baclofen. Sloughing with features of vacuolation of degeneration (black arrow) and detachment of sertoli cells (red arrow) (H\&E×400).

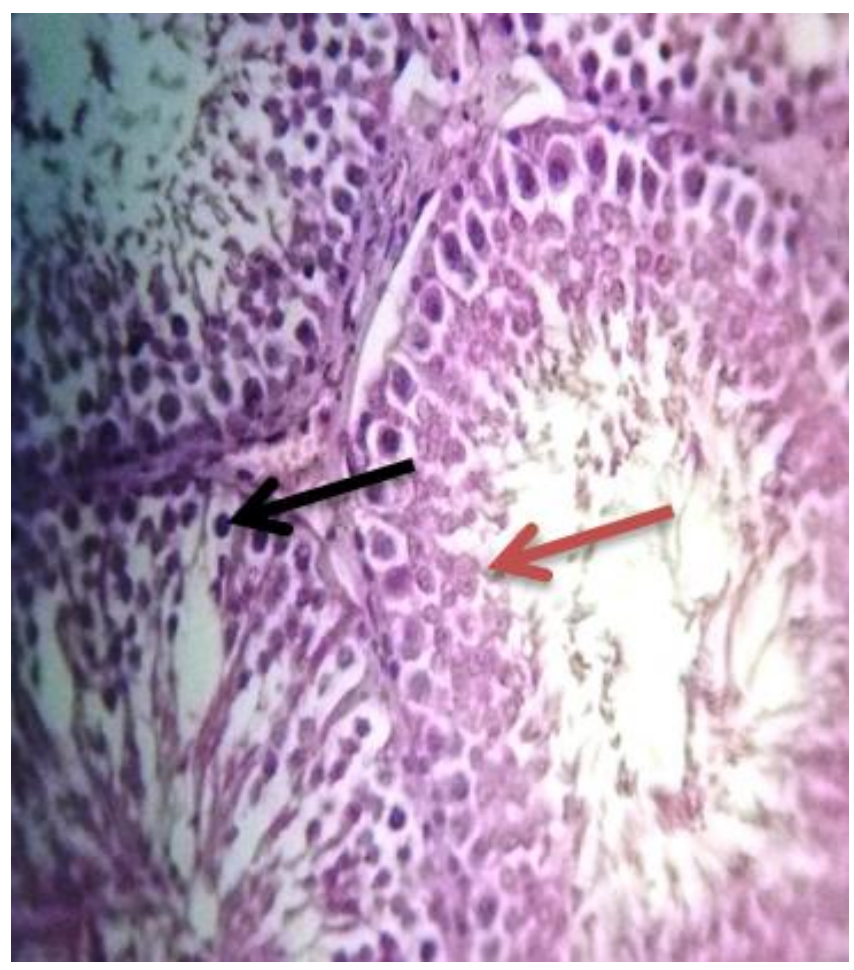

Figure 13: Photomicrograph of a testicular section of rat treated with baclofen with features of apoptosis (black arrows) and detached sertoli cells (red arrow) (H\&E×400). 


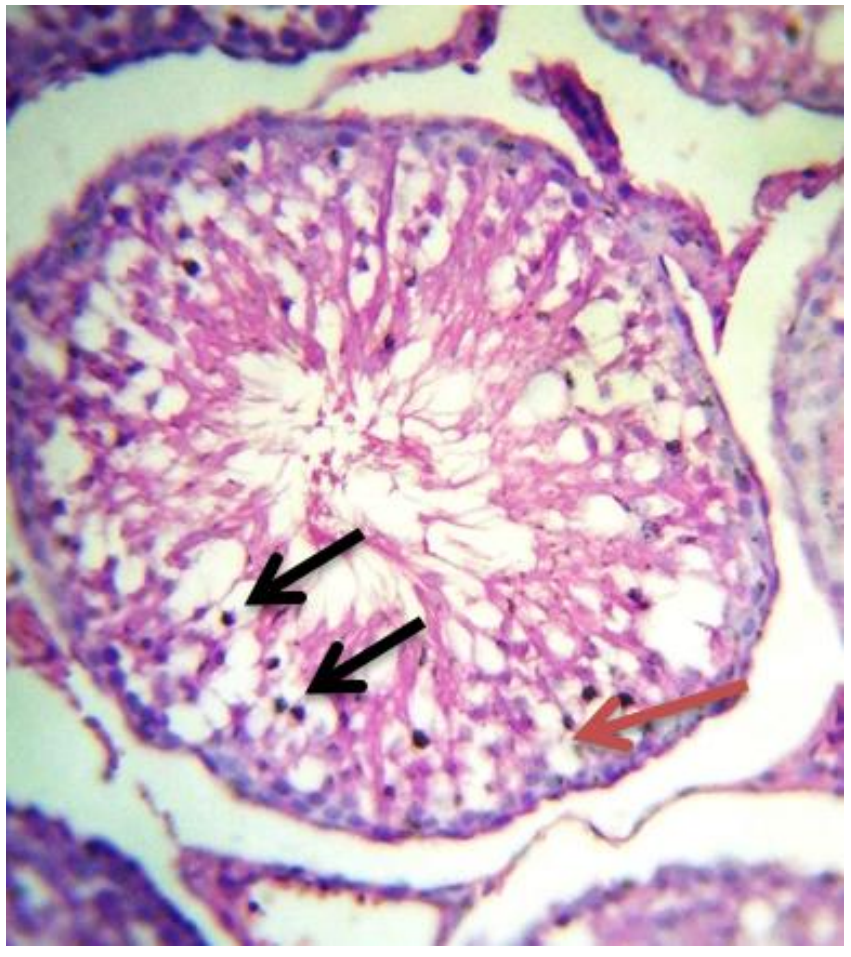

Figure 14: Photomicrograph of a testicular section of rat treated with baclofen with features of pyknotic nuclei (black arrows) and intraepithelial vacuoles (red arrow) (H\&E×400).

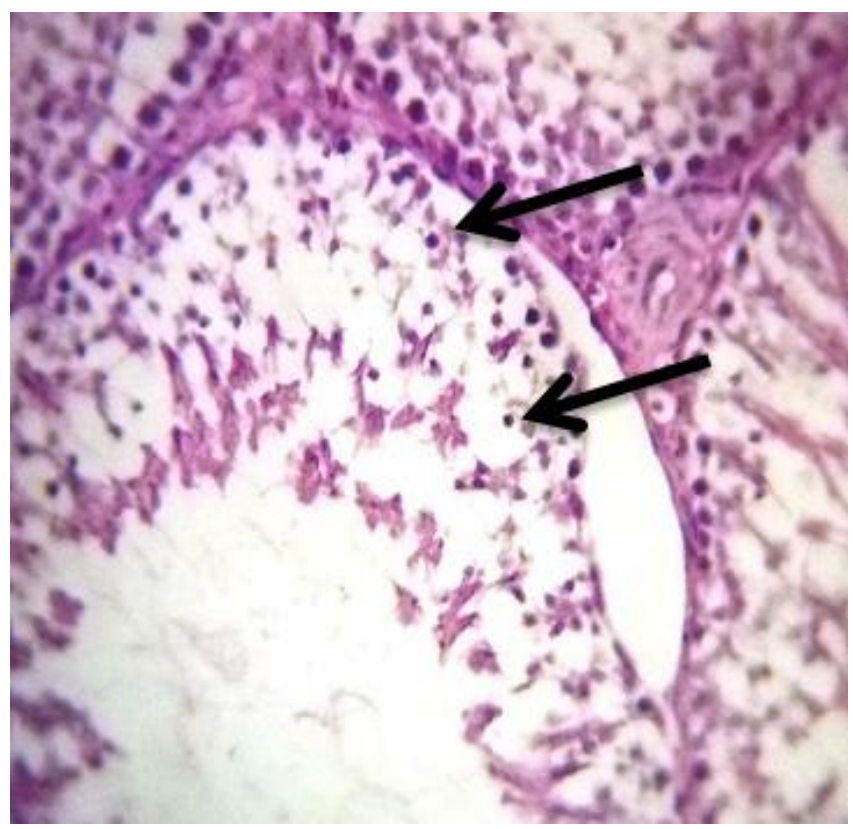

Figure 15: Photomicrograph of a testicular section of rat treated with baclofen with features of pyknotic nuclei (black arrows) (H\&E×400).

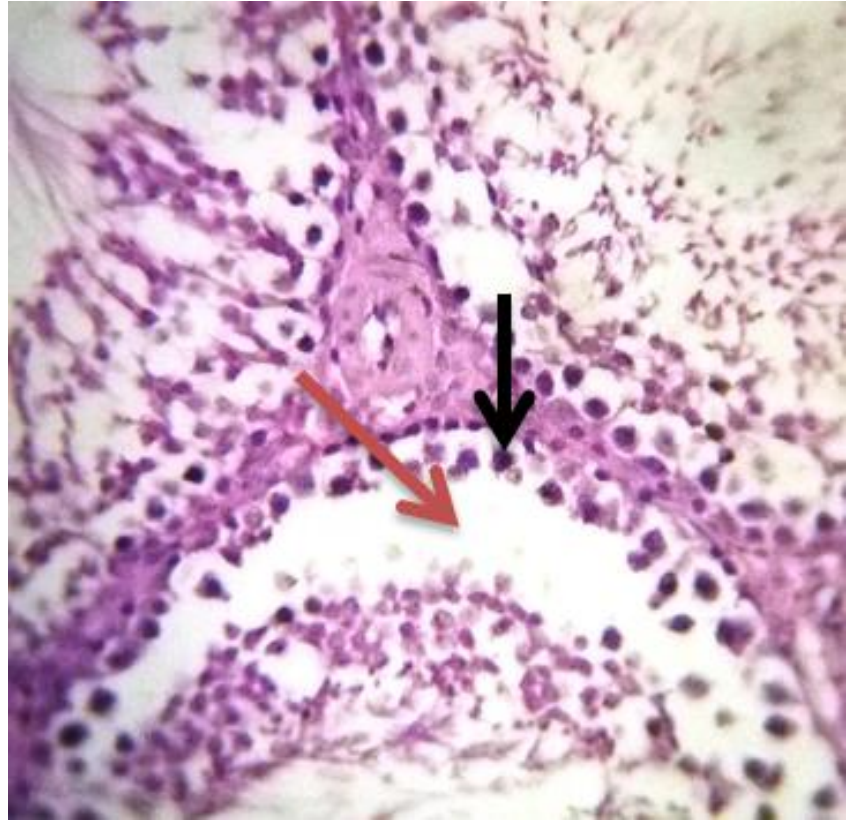

Figure 16: Photomicrograph of a testicular section of rat treated with baclofen with features of apoptosis nuclei (black arrows) and detachment from the basement membrane (red arrow) (H\&E×400).

\section{Discussion}

Pharmacological use of baclofen is widely increased all over the world, but its adverse effect has been poorly investigated. So, considering the paucity of researches on the effects of baclofen on males' reproduction, this work tried to assess its effects of sperm characteristics and testicular tissues in male rats. The $\gamma$-aminobutyric acid-GABA, is the chief neurotransmitter that inhibits the vertebrates' central nervous system as it has activated a spectrum of $\gamma$ aminobutyric acid receptor varieties. GABA neurotransmitted may be end via fast re-up taking its transporters into presynaptic neurons with glial cells that are surrounded them $(21,22)$. Previous published work revealed that $\gamma$-aminobutyric acid is localized in testes, sperms, deferent ducts and epididymis of males' reproductive system (6). In spite of the fact that $\gamma$-aminobutyric acid and its transporters - GAT1 distributed in the epididymis is unclear manner yet.

In fact, observation of GAT1 in testis, epididymis and sperms is reported $(22,23)$. GABA could has a physiologic regulatory role of sperms functions. Results of the sperm parameters in the two study groups revealed that there is a decrease in the percentage of live sperms in rats administered with $14.5 \mathrm{mg}$ of baclofen for 8 weeks in comparison with that of controls. Our observations are according with those of others who suggested that the characteristics measured by semen analysis are some of the factors in semen quality that 
determine the viability of sperm $(15,24)$. The multifacing procedure -spermatogenesis- can be influenced frequently by many faces to induce males' subfertility (25-27).

To our knowledge, there is no previous reports on the effect of baclofen administration on the sperm parameters in rats. Numerous factors may disturb spermatogenesis processes and affect sperms' quality and quantity (15), and the drugs are one of them $(12,17)$. The current work revealed different histological changes in testes of rats after exposure to baclofen for 8 weeks. In fact, the reports on the effect of this agents on the testicular histology in rats are scanty. Among the noticed testicular alterations were evidence of decreased Johnsen's scores (spermatogenic index), decrease in the number of seminiferous tubules containing spermatozoa, and disorganization of seminiferous tubules. Our observations are according those of other works $(23,28)$. Authors were considered the decrease in spermatogenic index represented by Johnsen's scores as an indicator of testicular injury functional impairment $(12,17,19)$. It has been reported that the overexpression of $\gamma$-aminobutyric acid transporter 1 may has an influence on the developing of mice testes. Observations of previous work suggested that the activation of GABAA receptors leads to stimulation. On the other hand, the activation of GABAB receptors causes inhibition $(21,23,28)$. These observations indicated that GABA and its receptors have a role crucially in reproduction. It has been reported that the injured germ cells are considered primarily morphological feature after exposure to pharmacological compounds $(12,18)$. Spermatogonial cells which is suffering from mitosis and the basic germ cell variety are without protection via the Blood Testes Barrier -BTB, are vulnerably affected to these agents.

On the other hand, light microscopic analysis of sections of rats administered with $14.5 \mathrm{mg} / \mathrm{kg} /$ day of baclofen for 8 weeks revealed presence of spermatogenic layer injury with vacuoles of degeneration in the seminiferous epithelium, and detachment of sertoli cells. Our observations are similar to those of Zang et al. who showed features of testes' dysplastic changes in GAT1 in transgenic mice (TG) with overexpression. Authors suggested that GAT1 when is expressed abnormally may causes defective spermiogenesis, presence of sperms paramorphia with dysgentic effects $(21-23,28)$. Authors suggested that these data may be useful for clinicians especially at the andrological aspects (5). GABA is crucial for the central nervous system's function (29) and it may be having the same influence on the testis. Due to the fact that the regulative function of the membranetransporting protein in GABA concentration, so GAT1 may share in spermatogenesis. Overexpressing GAT1 could cause a decrease in GABA concentration of testis of transgenic mice, thus inhibits testicular developing (21-23). So, the misregulated GAT1 results subfertility via influencing the development of sperms. Our observations also provide a possible impact of baclofen on cells of Sertoli, there is vacuolation of their cytoplasm, which may be caused by dilatation of endoplasmic reticulum. In fact, some Sertoli cell changes suggest that these cell damages are more obvious than those regarded as to be specifically secondary effects as an outcome from germ cell death (12), and it is in accompany with other alterations as including degenerative changes with spermatid retention, or the later alone (12). The Sertoli cells are vital in various key steps of spermatogenic lineage maturation and their resistance throughout the free radical attack may enhance the maintenance of seminiferous tubule integrity.

The current work showed features of sloughing of germ cells in sections of rats that are belonged baclofen group. The germ cells' exfoliation may be due to Sertoli cells dysfunction. The microtubule disruption leads to loosing of the attachments of germ cells to the processes of Sertoli cells, beside the sloughed germ cells (rounded spermatids, spermatocyte) inside the seminiferous tubules' lumens and finally to that of the excurrent ductules (30). On the other hand, apoptosis was found in sections of rats treated with baclofen. These lesions occur in a spontaneous manner to keep homoeostatic balance by diminishing injured germinative cells from the epithelia of tubules (21). Moreover, it is resulted from several challenges for examples: damage of DNA, thermal shocks, growth factors inhibition and stimulation of genes concerning with apoptosis, caspase serial events, and oxidative stress (27,3032). In addition, authors reported that GABA agonists exposure may induces apoptosis of germinative cells and also may injure cells of Leydig including the functional aspects (26). The inactivational influence of GABA results an inhibition of somatic stem cells proliferative action, the primary spermatogenic cells during spermatogenesis (27), beside the adverse effects of baclofen may be due to the involvement of GABA and transporter 1 (GAT1) in the Leydig cells' proliferations, testosterone's productions with spermatogenesis (25).

Another important lesion that should be concerned in this work is the retention of spermatids in sections of rats that are belonged to the baclofen's group. These observations are according with those of previous researchers who reported that retention of spermatids will result to defective spermiation (a process is regulated by Sertoli cells), and damages to these cells can change spermiation and lead to spermatid retention $(12,33)$. Like reported by authors the precise morphological alterations in rats' testes (included spermatids' retention and spermatocytes' degenerative changes and rounded spermatids are accompanied with diminished testosterone levels inside the testicular tissue $(12,18)$. As cells of Sertoli are exposed to toxicants for longtime, there is disruption of the seminiferous epithelial organization beside a spectrum of germ cell loosing and irregular array of germ cell layers. The cytoplasm of cell of Sertoli appeared obviously by the non-masking by germ cell loosing and which is scattered focally or segmentally, sometimes, it may be more extensive as in diffuse atrophy 
according to the degree of the severity of toxicities. Histopathological analysis of the testis is the gold method that is sensitively determine different influence on spermatogenetic process, but, the testicular histology is complex, interdisciplinary nature all cellular varieties in the testes, the prolonged spermatogenetic process can convert the evaluation of effect of any agent on the testicular compartments to a big challenge. An extensive detailed effort to understand the histological and morphological characters of response to damage is crucial to achieve a successful identification of the testicular influences and to start the understanding of mechanisms that is responsible for that (33). On the other hand, the testicular interstitial components were comparable between group 1 and group 2 , these findings were also consistent with those of another study (12), however, the morphologic changes in the cell of Leydig haven't been clearly noticed via light microscopic examination.

\section{Conclusion}

This study revealed that chronic administration of rats with $14.5 \mathrm{mg} / \mathrm{kg}$ with baclofen induced effects on both the sperm parameters and testicular histology, however, the testicular histological alterations were more obvious. Further works are needed to clarify the mechanisms of action that stands behind.

\section{Acknowledgment}

Deep thanks are presented for the staff of the Animal House of Animal house in College of Veterinary Medicine, University of Mosul for their kind cooperation. Authors are representing thanks to Professor Dr. Ghada Taqa, Department of Basic sciences, College of dentistry, University of Mosul for her helpful instructions. We are grateful to Dr. Amjad Hazim Al-Naemi, Department of Biochemistry, College of Medicine, University of Mosul for his excellent comments and to Dr. Ahmad Nazar Department of Anatomy, College of Veterinary Medicine, University of Mosul for his help.

\section{Conflict of interest}

Authors declared that there is no conflict of interest.

\section{References}

1. Aghaie S, Nikzad H, Mahabadi JA, Taghizadeh M, Azami-Tameh A, Taherian A, Sajjadian SM, Kamani M. Protective effect of combined pumpkin seed and ginger extracts on sperm characteristics, biochemical parameters and epididymal histology in adult male rats treated with cyclophosphamide. Anat Sci Int. 2016;91(4):382-390. DOI: 10.1007/s12565-015-0314-x

2. Russell LD, Russell JA, MacGregor GR, Meistrich ML. Linkage of manchette microtubules to the nuclear envelope and observations of the role of the manchette in nuclear shaping during spermeiogenesis in rodents. Am J Anat. 1991;192:97-120. DOI: 10.1002/aja.1001920202

3. Olshan AF, Mattison DR. Male mediated developmental toxicity. New York: Plenum Press;1994. 406 p.

4. Johnson L, Welsh THJ, Wilker CE. Anatomy and physiology of the male reproductive system and potential targets of toxicants. In: Boekleheide K, Chapin RE, Hoyer PB, et al, editors. Comprehensive toxicology. $1^{\text {st }}$ ed. Pergamon: New York; 1997. 5-61 p.

5. Zhang W, Qi L, Le W, Hu J, Guo L, Feng H, Zhang J. Differential distribution of GABA and GAT1 in mouse epididymis. Ann Clin Lab Res. 2017;5(4):203. DOI: 10.21767/2386-5180.1000203

6. Stephanie Z. Young, Angélique B. GABA's control of stem and cancer cell proliferation in adult neural and peripheral niches. Physiol. 2009;24(3):142-202. DOI: 10.1152/physiol.00002.2009

7. Holajova M, Franek M. Effect of short- and long-term administration of baclofen on spatial learning and memory in rats. Physiol Res. 2018;67(1):133-141. DOI: 10.33549/physiolres.933554

8. Knapp DJ, Overstreet DH, Breese GR. Baclofen blocks expression and sensitization of anxiety-like behavior in an animal model of repeated stress and ethanol withdrawal. Alcohol Clin Exp Res. 2007;31:582-595. DOI: $10.1111 / \mathrm{j} .1530-0277.2007 .00342 . \mathrm{x}$

9. Zhang C, Zhang R, Zhang S, Xu M, Zhang S. Baclofen for stroke patients with persistent hiccups-A randomized double-blind, placebocontrolled trial. Trials. 2014;15:295-298. DOI: 10.1186/1745-6215-15295

10. Liu HJ, Wise SG, Rnjak-Kovacina, Kaplan DL, Bilek MM, Weiss AS, Fei J, Bao S. Biocompatibility of silk-tropoelastin protein polymers. Biomaterials. 2014;35:5138-5147. DOI: 10.1016/j.biomaterials.2014.03

11. Material Safety Data Sheet Baclofen MSDS last updated at 2012 by science lab for chemical and laboratory equipment. [available here]

12. Al-Allaf LK, Al-Ashoo HA. The effect of CO-Q10 on the testicular histological changes in rats induced by imatinib. Iraqi $\mathrm{J}$ Vet Sci. 2021;35(1):189-196. DOI: 10.33899/ijvs.2020.126587.1347

13. Al-Allaf LK, Al-Ashoo HA. A histological study on the effect of imatinib on the rats' testis after early postnatal exposure. Iraqi J Vet Sci. 2021;35(1):189-196. DOI: 10.33899/ijvs.2020.126587.1347

14. Jalili C, Kamani M, Roshankhah S, Sadeghi H, Salahshoor MR. Effect of falcaria vulgaris extracts on sperm parameters in diabetic rats. Androl. 2018;50:e13130. DOI: 10.1111/and.13130

15. Roshankhah SH, Salahshoor MR, Aryanfar S, Jalili F, Sohrabi M, Jalili C. Effects of curcumin on sperm parameters abnormalities induced by morphine in rat. J Med Biomed Sci. 2017;6:1-10. DOI: 10.4103/22779175.251209

16. Jalili C, Salahshoor MR, Khani F, Roshankhah SH. protective effect of curcumin against nicotine-induced damage on reproductive parameters in male mice. Int J Morphol. 2014;32:869-874. DOI: 10.4067/S071795022014000300017

17. Aksu EH, Kandemir FM, Özkaraca M, Ömür AD, Küçükler S, Çomaklı S. Rutin ameliorates cisplatin-induced reproductive damage via suppression of oxidative stress and apoptosis in adult male rats. Androl. 49(1):e12593. DOI: $10.1111 /$ and.12593

18. Tanriverdi O, Unubol M, Taskin F, Meydan N, Sargin G, Guney E, Barutca S. Imatinib-associated bilateral gynecomastia and unilateral testicular hydrocele in male patient with metastatic gastrointestinal stromal tumor: A literature review. J Oncol Pharm Pract. 2012;18(2):303-10. DOI: 10.1177/1078155211424629

19. Ramos SDP, Goessler KF, Ruiz RJ, Osny Ferrari, Polito MD, Salles MJS. Exercise protects rat testis from cyclophosphamide-induced damage. Acta Scientiarum. Biol Sci Maringá. 2013;35(1):105-113. DOI: $\underline{10.4025 / \text { actascibiolsci.v35i1.12475 }}$

20. Roshankhah S, Cyrus Jalili C, Salahshoor MR. Effects of crocin on sperm parameters and seminiferous tubules in diabetic rats. Adv Biomed Res. 2019;8:4. DOI: 10.4103/2277-9175.251209

21. Zhang JF, Gui YP, Yuan T, Bian C, Guo L. Expression of GAT1 in male reproductive system and its effects on reproduction in mice. Sys Biol in Reprod Med. 2009;55:175-180. DOI: $\underline{10.3109 / 19396360903030500}$ 
22. Ma YH, HU J, ZHOU X, Zeng RW, Mei ZT, Fei J, Guo LH. Transgenic mice overexpressing $\gamma$-aminobutyric acid transporter subtype I develop obesity. Cell Res. 2000;10:303-310. DOI: 10.1038/sj.cr.7290057

23. Hu JH, Zhang JF, Ma YH, Jiang J, Yang N, Li XB, Yu Chi ZG, Fei, J, Guo LH. Impaired reproduction in transgenicmice overexpressing $\mathrm{g}$ aminobutyric acid transporter I (GAT1). Cell Res. 2004;14:54-59. DOI: 10.1038/sj.cr.7290202

24. Kadir ER, Ojulari LS, Ibrahim A, Ekundayo OJ, Jaji-Sulaimon R, Jimoh-Abdulghaffaar HO. Testicular morphology and seminal fluid parameters of adult Wistar rats following honey administration. Trop J Pharmaceut Res. 2018;17(7):1331-1335. DOI: 10.4314/tjpr.v17i7.15

25. Taherianfard M, Bahaddini A, Keshtkar S, Fazeli M, Shomali T. Effect of Extremely Low Frequency Electromagnetic Field and GABAA Receptors on Serum Testosterone Level of Male Rats. Int J Endocrinol Metab. 2013;11. DOI: 10.5812/ijem.11029

26. Nudmamud-Thanoi $S$, Thanoi S. Methamphetamine induces abnormal sperm morphology, low sperm concentration and apoptosis in the testis of male rats. Androl. 2011;43:278-282. DOI: $\underline{10.1111 / j .1439-}$ 0272.2010.01071.x

27. Du Y, Du Z, Zheng H, Wang D, Li S, Yan Y, Li Y. GABA exists as a negative regulator of cell proliferation in spermatogonial stem cells. Cell Mol Biol Lett. 2013;18:149-162. DOI: 10.2478/s11658-013-00814

28. Hu JH, He XB, Wu Q,Yan YC, Koide SS. Biphasic effect of GABA on rat sperm acrosome reaction: Involvement of GABA A and GABA B receptors. Arch Androl. 2002;48(5):369-378. DOI: 10.1080/01485010290099246

29. Varju P, Katarova, Z, Madara' sz, E, Szabo' G. GABA signaling during development: new data and old questions. Cell Tissue Res. 2001;305:239-246. DOI: 10.1007/s004410100356

30. Kaewman P, Nudmamud-Thanoi S, Thanoi S. GABAergic alterations in the rat testis after methamphetamine exposure. Int J Med Sci. 2018;15(12):1349-1354. DOI: 10.7150/ijms.27609

31. Lee J, Richburg JH, Shipp EB, Meistrich ML, Boekelheide K. The Fas system, a regulator of testicular germ cell apoptosis, is differentially upregulated in Sertoli cell versus germ cell injury of the testis. Endocrinol. 1999;140:852-858. DOI: $10.1210 /$ endo.140.2.6479

32. Kim R, Tanabe K, Uchida Y, Manabu Emi M, Inoue H, Toge T. Current status of the molecular mechanisms of anticancer drug-induced apoptosis. The contribution of molecular-level analysis to cancer chemotherapy. Cancer Chemother Pharmacol. 2002;50:343-352. DOI: 10.1007/s00280-002-0522-7

33. Vidal J, Whitney KM. Morphologic manifestations of testicular and epididymal toxicity. Spermatogenesis. 2014;4(2):e979099. DOI: $\underline{10.4161 / 21565562.2014 .979099}$

\section{هل يحدث الباكلوفين تغييرات في نسيج الخصية وتحليل السائل المنوي لأى الجرذان؟}

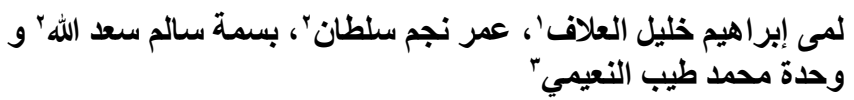

'فرع التشريح، كلية الطب، 'فرع العلوم الأساسية، كلية طب الأسنان،

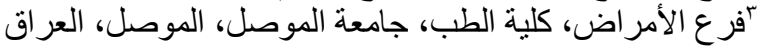

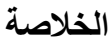

إن للباكلوفين تأثيره المركزي مما جعله يستعمل بشكل رئيسي

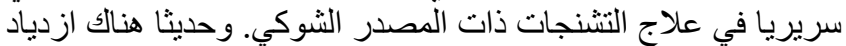

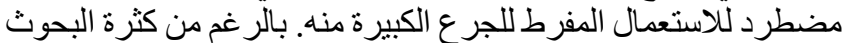

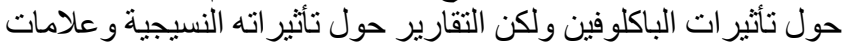

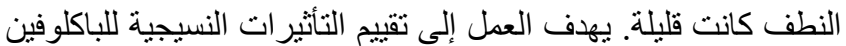

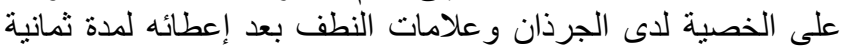

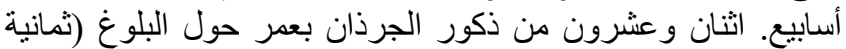

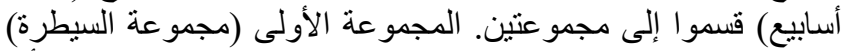

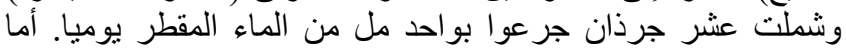

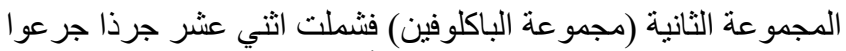

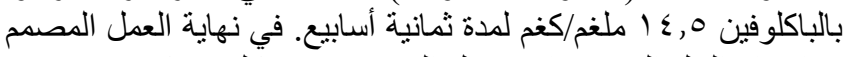

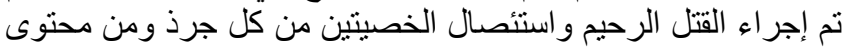

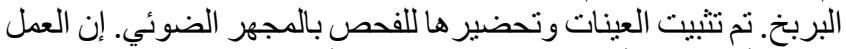

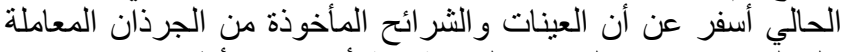

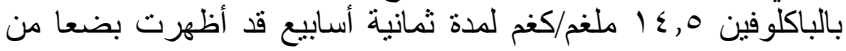

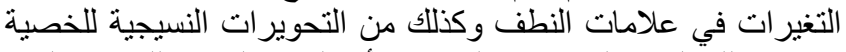

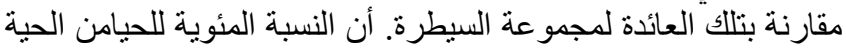

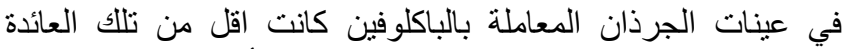
لمجموعة السيطرة. كانت علامات للتسلخ داخل التبل أوعية النبيبات الناقلة

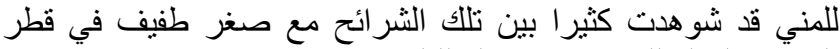
النبيبات الناقلة للمني. وجود ادله للقلة في معايير جونسين التين (معيار تكوين

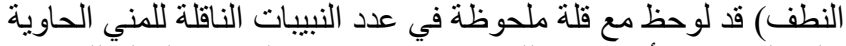

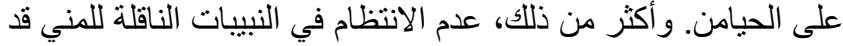

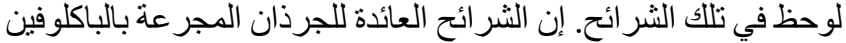

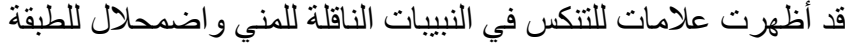

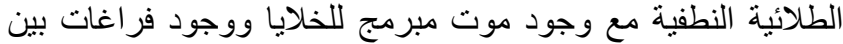

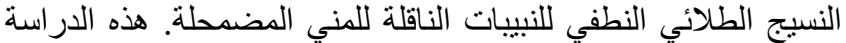

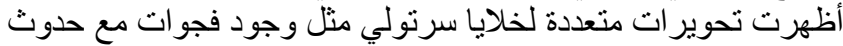

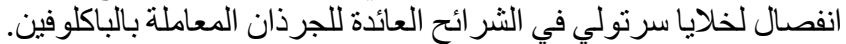

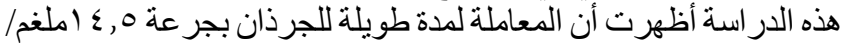

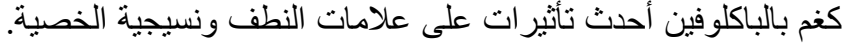

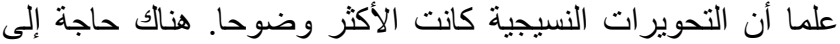
أعمال أخرى لتوضيح الألية التي تقف ور اء حدوث تلات التئ التأثيرات. 